\title{
TRAJETÓRIA DE VIDA DE TREINADORES DE SURFE: ANÁLISE DOS SIGNIFICADOS DE PRÁTICA PESSOAL E PROFISSIONAL
}

\author{
Valmor Ramos
}

Universidade do Estado de Santa Catarina, Florianópolis, Santa Catarina, Brasil.

Vinicius Zeilmann Brasil

Universidade Federal de Santa Catarina, Florianópolis, Santa Catarina, Brasil.

Thais Emanuelli da Silva de Barros

Universidade Federal de Santa Catarina, Florianópolis, Santa Catarina, Brasil.

Ciro Goda

Universidade Federal de Santa Catarina, Florianópolis, Santa Catarina, Brasil.

\section{Jonas Godtsfriedt}

Universidade Federal de Santa Catarina, Florianópolis, Santa Catarina, Brasil.

\begin{abstract}
Resumo
O objetivo deste estudo foi descrever situações da trajetória de vida de treinadores de surfe, identificando os significados que atribuem à prática pessoal e profissional neste esporte. Realizou-se uma pesquisa qualitativa com 11 profissionais de reconhecida competência. Foi utilizada entrevista semiestruturada. Os dados foram analisados a partir da técnica de análise de conteúdo. Os resultados mostram que as situações de lazer em família foram importantes para o ingresso no contexto do surfe. As experiências de prática pessoal e os amigos foram importantes para se tornarem treinadores. Concluiu-se que alguns significados pessoais de prática destes sujeitos permaneceram estáveis ao longo da vida influenciando a escolha e permanência na carreira de treinador.
\end{abstract}

Palavras chave: Valores Sociais. Educação Física e Treinamento. Esportes.

\section{Introdução}

Os valores humanos são elaborados a partir de um processo contínuo de socialização que ocorre ao longo da vida desde a infância até a vida adulta, no qual o indivíduo incorpora significados, aprende padrões sociais normativos, comportamentais e habilidades de uma cultura específica com im- 
plicações importantes na aquisição de sua identidade pessoal (DORSCH; SMITH; MCDONOUGH, 2009).

Dentro de um sistema de crenças, os valores apresentam uma posição mais central, ligados à emoção, conferindo uma natureza mais estável ao longo da vida. Quando são ativados despertam sentimentos e pensamentos avaliativos (positivos/negativos), criando critérios pessoais de escolha sobre algo e ideais de conduta sobre os outros e sobre si próprio (GAU; KORZENNY, 2009; LEE; WHITEHEAD; BALCHIN, 2000; MACLEAN, 2008; ROKEACH, 1981; SCHWARTZ, 2005).

Investigações realizadas com universitários da área de Educação Física mostram que algumas crenças se mantiveram estáveis ao longo da vida, influenciando em muitas decisões pessoais e profissionais. $\mathrm{O}$ ingresso nos programas de formação inicial, por exemplo, bem como o direcionamento durante a vida universitária e a prática pedagógica, são determinados pelas experiências prévias trazidas da prática pessoal (HENRIQUE; FREITAS, 2009; O'SULLIVAN, 2005; RAMOS; GRAÇA; NASCIMENTO, 2006, RAMOS et al., 2011; TSANGARIDOU, 2008).

No contexto esportivo, estudos mostram que a participação e o envolvimento de jovens no esporte têm implicações positivas no desenvolvimento da personalidade e na aprendizagem. Honestidade, compaixão, cooperação, disciplina, liderança, autocontrole são exemplos de valores aprendidos através do esporte, desempenhando papel importante na busca do êxito pessoal e da convivência social ao longo da vida (CÔTÉ; ERICKSON; ABERNETHY, 2013; FORNERIS; CAMIRÉ; TRUDEL, 2012; FRASERTHOMAS; COTÉ, 2009; HOLT; NEELY, 2011).

Para MacLean e Hamm (2008), Martens (2002), Lee, Whitehead e Balchin (2000), a natureza estável dos valores e o nível de influência que os professores ou treinadores de jovens exercem sobre seus aprendizes são motivos importantes para a realização destas pesquisas com estes profissionais. As ações dos treinadores e professores ultrapassam as responsabilidades formais de ensinar conteúdos, transmitindo voluntária ou involuntariamente modos de pensar e agir que influenciam as decisões de vida de seus alunos.

Os significados e valores atribuídos ao esporte interferem fortemente nos objetivos ou direcionamentos pedagógicos de ensino que os treinadores esportivos realizam. Eles influenciam na escolha dos conteúdos, nas estratégias pedagógicas a serem adotadas, nas formas de avaliação de aprendizagem, nos recursos, condicionando, enfim, as decisões para aceitar, priorizar ou rejeitar elementos para a sua intervenção pedagógica (ENNIS, 1994; RAMOS, 2008; GROSSMAN, 1990; GRAÇA, 1999).

Neste sentido, o objetivo deste estudo foi descrever situações da trajetória de vida pessoal e profissional de treinadores de surfe para jovens, identificando as implicações das experiências na definição dos significados 
e valores sociais que atribuem à prática pessoal e profissional no ensino deste esporte.

\section{Método}

Realizou-se pesquisa qualitativa do tipo descritiva com caráter interpretativo, com ênfase no contexto e nos processos socioculturais de construção dos dados (BOGDAN; BIKLEN, 2003; ALVES-MAZZOTTI; GEWANDSZNAJDER, 2004). O pesquisador é tido como instrumento investigativo, recolhendo informações de forma direta, em contextos naturais e a partir de pequenas amostras. Seguindo-se, assim, uma análise indutiva dos dados (GIL, 2008; LAKATOS; MARCONI, 2010).

\section{Sujeitos do estudo}

As etapas de seleção dos sujeitos foram semelhantes a estudos realizados por Gilbert e Trudel (2004) e Abraham, Collins e Martindale (2006). Assim: a) identificou-se a entidade especializada na gestão do surfe, reconhecida legalmente em Florianópolis e que tivesse realizado algum processo de formação profissional nos últimos anos; b) realizou-se consulta com os dirigentes e treinadores formadores desta associação, a fim de identificar os treinadores que estavam cadastrados na associação e credenciados no Conselho Regional de Educação Física; c) os treinadores foram consultados para verificarmos as seguintes características: possuir o mínimo de cinco anos de experiência no ensino do surfe em escola especializada; expressar motivação e disponibilidade para participar do estudo; estar atuando no ensino durante o período da pesquisa; dedicar-se integralmente ou prioritariamente à atividade de ensino do surfe; possuir reconhecimento profissional diante dos seus pares. Dentre o total de 16 treinadores, 11 atenderam aos critérios de inclusão e foram convidados a participar do estudo. Sendo 10 do sexo masculino e uma do sexo feminino, com idade entre 28 e 52 anos.

Todos os sujeitos praticam surfe desde a infância, tendo experiência média de prática pessoal de 27 anos (min. 20 anos; máx. 40 anos). O tempo médio de experiência de prática profissional no surfe foi de 18 anos (min. 8 anos; máx. 30 anos). A utilização do termo treinadores para designar os sujeitos, decorre da literatura internacional que identifica o treinador de jovens como aquele que realiza uma prática pedagógica visando a formação esportiva de jovens, seja para uma participação em práticas de lazer ou formação para competições na idade adulta (TRUDEL; GILBERT, 2006).

\section{Instrumento de coleta dos dados}

Pensar a Prática, Goiânia, v. 17, n. 3, p. 815-834, jul./set. 2014 
Um roteiro de entrevista semiestruturada foi utilizado para a coleta de dados. Neste procedimento, o investigador interroga o entrevistado com questões ordenadas a priori, podendo acrescentar novos questionamentos no decorrer da entrevista para aprofundar ou obter respostas mais completas sobre a temática (NEGRINE, 2004). O roteiro foi elaborado a partir da adaptação do estudo de Ramos (2008), com o objetivo de garantir a validade de construção e de conteúdo. As perguntas permitiram obter a descrição dos sujeitos a respeito das suas percepções sobre sua biografia no âmbito do surfe. As questões versaram sobre as experiências marcantes para seu ingresso e permanência na prática pessoal do surfe, bem como para a sua prática profissional.

\section{Procedimentos de coleta dos dados}

As entrevistas foram realizadas em local previamente determinado, conforme a conveniência dos treinadores. As respostas foram captadas por meio de um gravador digital e armazenadas em um micro computador. Todas foram transcritas literalmente com o auxílio dos programas Windows Media Player e Word, e analisadas com o uso do programa QSR Nvivo.

Todos os participantes assinaram o respectivo termo de consentimento para a gravação e divulgação dos dados. O projeto foi avaliado pelo Comitê de Ética em Pesquisa com Seres Humanos em universidade pública no Brasil (Parecer $\mathrm{n}^{\circ}$ 187/2009-UDESC). Para preservar o anonimato dos investigados, cada sujeito esta identificado no texto por letras e números (T1, T2, $\mathrm{T} 3 \ldots)$.

\section{Análise dos dados}

A análise dos dados foi realizada a partir da técnica de análise de conteúdo, na qual o investigador busca categorizar as palavras ou frases contidas no texto que se repetem, inferindo uma expressão que as representem. Este processo se dá através de três fases principais: organização dos dados, identificação das unidades de análise e a organização dos resultados (BARDIN, 2010).

$\mathrm{Na}$ primeira fase deste estudo foram organizadas as informações através da transcrição das entrevistas. A segunda fase correspondeu à exploração do material e codificação dos textos ou transcrições brutas em representações de conteúdo, identificando as unidades de significado. Na terceira fase foram realizadas a contagem da frequência das unidades de análise e a organização dos resultados.

Para conferir validade descritiva e interpretativa, foram empregados procedimentos de checagem pelos participantes (MOLINA NETO; TRI- 
VIÑOS; SANCH, 2004; ALVES MAZZONTTI; GEWANDSZNADJER, 2004), nos quais as descrições foram enviadas aos sujeitos para que se manifestassem sobre a veracidade das mesmas, reconhecendo-as e confirmando-as.

\section{Resultados}

Os dados na Figura 1 são organizados a partir da seleção e descrição de uma sequência de episódios, com base nas percepções dos treinadores a respeito dos seus percursos de participação no surfe.

\section{Figura 1: A experiência de prática pessoal e profissional dos treinadores de surfe}

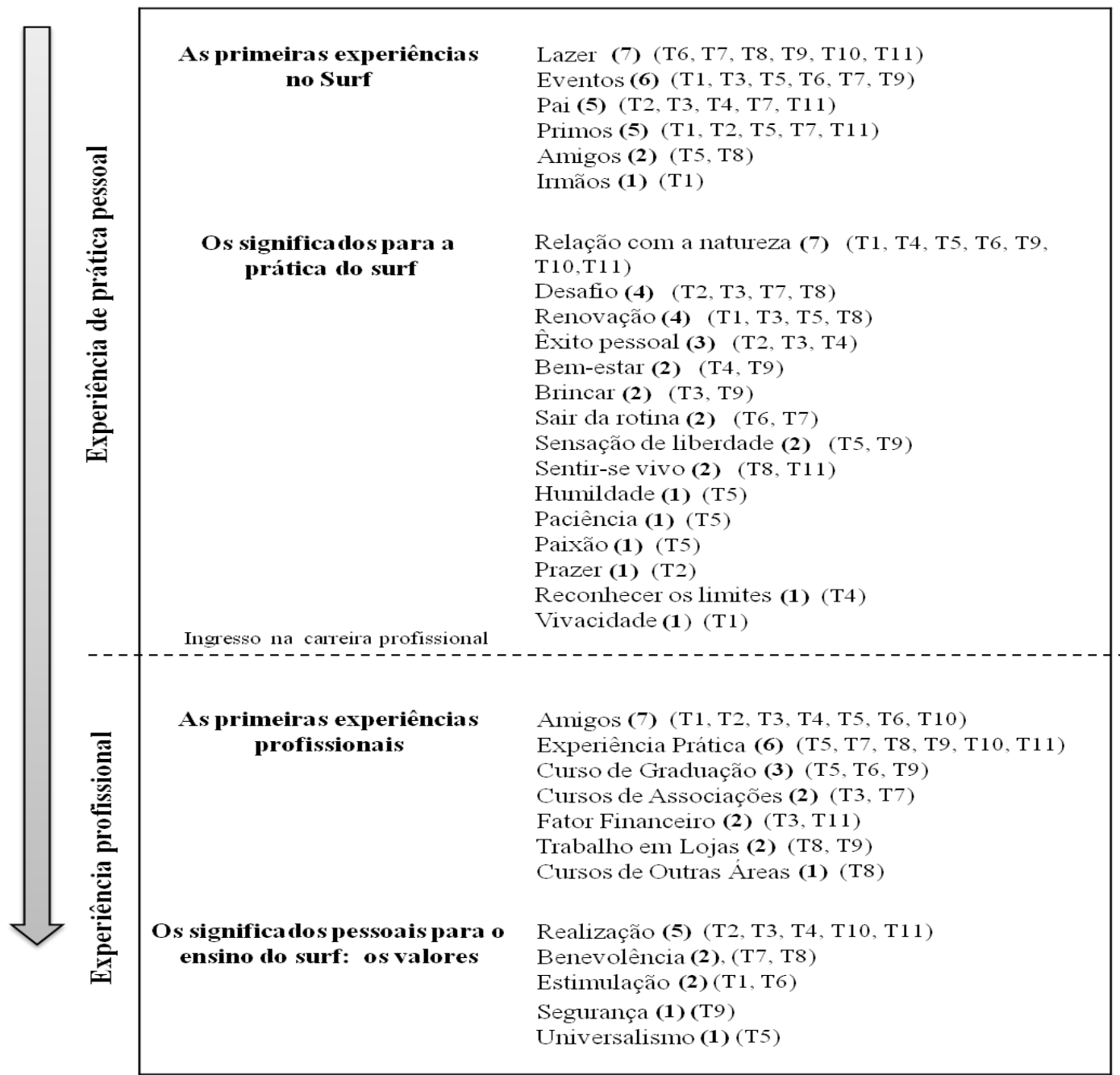

Pensar a Prática, Goiânia, v. 17, n. 3, p. 815-834, jul./set. 2014 


\section{As experiências de prática pessoal no surfe}

Os resultados na Figura 1 mostram que as situações de lazer de verão foram aquelas nas quais a maioria dos treinadores obtiveram o primeiro contato com o surfe. Sete sujeitos, (T4, T6, T7, T8, T9, T10, T11) indicaram que as suas primeiras experiências se deram nestas circunstâncias. A segunda experiência mais citada foi aquela obtida nos eventos de surfe, totalizando seis indicações (T1, T3, T5, T6, T7, T9), onde os treinadores, ainda na fase da infância, foram levados a participar como expectadores.

Destaca-se que estas experiências de lazer e eventos estiveram quase sempre associadas a contextos sociais imediatos. O primeiro contato com o contexto do surfe ocorreu por influência direta dos pais (5), primos (5), amigos (2), ou irmãos (1). Assim, apresentam-se alguns excertos das entrevistas dos sujeitos que ilustram esta interpretação. A seguir, o Treinador 4 (T4) relembra episódios das férias de verão com a família:

[...] eu me lembro de vir para a praia quando criança, vir para a praia e ver meu pai surfando, ou saindo da praia, da água com a prancha e outras pessoas surfando, então isso, para quem nasceu, para quem mora aqui é uma coisa que tu já tem contato. (T4).

O Treinador 3 relembra de quando acompanhou seu pai, fotógrafo/cinegrafista, em evento de surfe internacional em sua cidade: "“[...] mas, realmente foi a partir do campeonato Hang Loose de 1986 que eu tive o primeiro contato e me interessei pela prática deste esporte[...]" (T3).

Um dos significados atribuídos pelos treinadores à prática pessoal e que os motivaram a permanecerem envolvidos no contexto do surfe foi a relação com a natureza, indicada por sete sujeitos (T2, T4, T5, T6, T9, T10, T11). A seguir, um excerto ilustrativo de um dos treinadores: "[...] eu acredito que o ser humano também é natureza, aí se confunde, a gente, o ser humano, ele é a própria natureza também[...]” (T10).

O segundo significado mais citado diz respeito à renovação, citado do por T1, T3, T5 e T8. Nos termos do treinador 8 (T8), renovação refere-se ao: "[...] sentimento de viver todo dia, todo momento redescobrindo algo dentro d'água[...]". A busca por desafios, também foi considerada por T2, T3, T7 e T8 como fator motivacional para a permanência no surfe, conforme a fala abaixo:

[...] na água, aquela adrenalina também de descer uma onda, de pegar uma maior. Eu lembro que desde de moleque eu queria pegar a maior, a maior, a maior, a maior. 
Hoje em dia já sou mais sossegado... Mas na época a emoção era pegar onda grande, porque, até não tinha muito.(T3).

Outros foram citados pelos treinadores e evidenciam a variedade de significados para a prática: êxito pessoal (T2, T3, T4); bem-estar (T4, T9); brincar (T3, T9); sair da rotina (T6, T7); sensação de liberdade (T5, T9); sentir-se vivo (T8, T11); humildade (T5); paciência (T5); paixão (T5); prazer (T2); reconhecer seus limites (T4); vivacidade (T1).

\section{As experiências profissionais}

O ingresso na carreira profissional de T1, T2, T3, T4, T5, T6 e T10 ocorreu "naturalmente" e ou por "amigos". Ou seja, através de um convívio social com pessoas mais próximas e através de um envolvimento contínuo nas diversas atividades de um contexto circunscrito à área do surfe, conforme excerto: "[...] meu amigo abriu uma escola de surfe na praia, e começou a dar aula e ele me chamava pra ajudar ele a montar a barraca na praia, ficar ali com a galera organizando [...]" (T1).

$\mathrm{O}$ segundo elemento mais citado para o ingresso na carreira foram as experiências de prática pessoal na modalidade (T5, T7, T8, T9, T10, T11):

[...] é na prática que tu adquire esse conhecimento, na prática mesmo! Horas e horas e horas de água mesmo, prática no ambiente direto ali, diferentes situações, diferentes condições, aprendendo a surfar uma onda ridícula e uma onda enorme. Desafiando também um pouco, indo até o teu limite, entendeu. (T11).

Estar cursando graduação também foi referenciado por T5, T6 e T9 como um fator importante para o ingresso na carreira de treinador, porém, somente os dois últimos citados cursavam Educação Física. As situações de cursos de Associações (T3, T7), trabalho em lojas do gênero moda surfe (T8, T9); busca de rendimento ou fator financeiro (T3, T11), além de cursos em outras áreas ligadas ao mar foram citadas (T8).

Destaca-se que os treinadores T1, T2, T3, T4, T5 e T6 afirmaram explicitamente que suas metas de ensino estão diretamente relacionadas aos seus próprios objetivos de prática pessoal, construídos ainda na infância, indicando o impacto da experiência de prática pessoal e a manutenção dos significados pessoais em sua atividade pedagógica cotidiana.

Os significados podem ser interpretados a partir da tipologia de valores de Schwartz (2005), conforme Figura 1. Os valores estão na base de um processo de motivação das pessoas e podem ser classificados em: a) valores 
de caráter mais pessoal, nomeadamente valores de Autodeterminação; Estimulação; Hedonismo; Realização; Poder. b) valores que favorecem mais ao coletivismo e que tem maior relação com a aceitação social, respectivamente os valores de Universalismo, Benevolência; Tradição; Conformidade; Segurança.

Nesta perspectiva, o Treinador 1 (T1) busca transferir ao outro a cultura do surfista que ele tanto aprecia e os significados que ele atribui à sua própria prática pessoal da modalidade, especificamente, a vivacidade e renovação da condição de ser criança que a prática do surfe e a relação com a natureza proporcionam. Este é um significado mais ligado aos valores de Estimulação.

No caso particular de T2, ensinar é fazer com que o aluno tenha as mesmas sensações de bem estar e sucesso diante do desafio de percorrer uma onda, semelhante àquela que ele alcançava quando iniciou sua prática. Isso está ligado aos valores de Realização. Para T3, seu objetivo é primordialmente fazer com que o aluno possa surfar e levá-lo assim a algum êxito, como ficar em pé numa onda, evidenciando também valores de Realização. Para T4, o ensino direciona-se para a sensação de competência dos seus alunos, sua satisfação surge quando o aluno aprende a surfar e tem êxito na onda, semelhante ao sentimento que desfruta quando ele mesmo surfa. Ligado também a valores de Realização.

Para T5, o objetivo do seu ensino é proporcionar aos alunos a sensação de liberdade no contato com a natureza e as trocas de energia que esta relação proporciona. Ele acredita que há uma aprendizagem constante nesta relação do surfista com a natureza que deve ser enfatizada e se traduz no reconhecimento dos limites pessoais do praticante, nos sentimentos de humildade e paciência para agir neste ambiente natural e no mar, especificamente. Estes significados do ensino são interpretados neste estudo como valores de Universalismo.

Ensinar, para T6, é sempre uma troca que envolve reciprocidade entre professor e aluno, de modo que sua satisfação é transferir aos alunos a percepção de que o contato com a natureza, na pratica do surfe em particular, é sempre uma possibilidade de aprender algo novo e de levar uma vida esportiva dotada de experiências variadas, em oposição aos esportes tradicionais. Este significado remete a valores individuais de Estimulação.

Sem expressar relação direta com os valores adquiridos através da experiência pessoal de prática na infância, verificou-se que o Treinador 7 (T7) busca criar no aluno um sentimento de confiança quanto à qualidade do seu trabalho, estabelecendo, a partir disso, relações de amizade mais profícuas e duradouras. Seus sentimentos de responsabilidade, lealdade e busca de amizade nas relações, durante o ensino, evidenciam valores de Benevolência. 
Também com relação aos valores de Benevolência, o Treinador 8 (T8) indica que nas suas aulas sempre busca auxiliar o aluno na conquista do sonho de aprender a surfar, ele acredita que cada um que ajuda a aprender torna-se um grande amigo para a vida. Seu objetivo primordial no ensino é estabelecer esta relação de amizade e lealdade entre aluno professor/treinador.

O ensino de T9 é guiado pelo propósito de levar seu aluno ao reconhecimento dos benefícios que a prática do surfe proporciona na relação com a natureza. As atividades na natureza são sempre manifestação de liberdade e uma oportunidade de "desestresse", como ele mesmo denomina. Isso leva a crer que o treinador promove sentimentos de integração com a natureza e de saúde e equilíbrio mental, propiciados pelo ambiente, e respectivamente ligados a valores de Segurança.

Para T10, sua intervenção busca tornar os seus alunos mais competentes na prática do surfe. Sua perspectiva é ensinar o "modo correto de surfar" levando-os a se sentirem eficientes e bem sucedidos no que realizam. Acredita-se que estes propósitos estejam ligados aos valores de Realização. Atribuindo valores sociais semelhantes, T11 busca com a iniciação esportiva identificar e aperfeiçoar as aptidões esportivas dos seus alunos, criando a possibilidade de se tornarem atletas profissionais no futuro.

\section{Discussão}

Os resultados mostram que as primeiras experiências dos sujeitos na prática do surfe ocorreram na infância e estiveram ligadas ao lazer e aos contextos de relações sociais mais imediatos, particularmente através de um processo de socialização, proporcionado pelos integrantes da família e amigos.

Paralelamente às relações sociais influenciadoras ao ingresso na prática pessoal, pode-se sugerir a ocorrência de um processo de socialização esportiva, particularmente através dos integrantes da família e amigos. Entendendo a socialização como um processo pelo qual as pessoas adquirem comportamentos e crenças ou a cultura do meio social onde elas vivem, sendo a família, pares, comunidade, escola, meios de comunicação, sistema de leis, normas e crenças sociais, respectivamente as principais fontes de socialização (ARNETT, 1995).

Em um processo de socialização, a família é o contexto inicial e central para as crianças, sendo responsável pela internalização de significados que servirão de base para a formação de todos os demais pensamentos e sentimentos ao longo da vida. Muitos dos contextos culturais vividos pelos filhos representam a extensão das experiências que os próprios pais tiveram (SCHWARTZ, 2005; ARNETT, 1995). 
A família, interpretada a partir da teoria dos sistemas de Bertalanffy (1977), configura-se como um subsistema social, e os seus familiares como elementos interdependentes que podem pertencer a mais de um subsistema social. O pai, primo ou irmão, ao mesmo tempo em que convivem e interagem com membros de um mesmo ambiente familiar, interagem e participam de outros contextos (escolas, clubes, instituições, associações, espaços de prática), favorecendo um intercâmbio de informações e valores entre componentes de um grupo e outro.

Assim, o papel dos familiares na introdução destes treinadores no surfe, ainda na fase de infância, não foi propriamente o compartilhamento direto dos valores deste esporte dentro do ambiente familiar. Foi, principalmente, a criação de oportunidades para que houvessem experiências de lazer na praia (ambiente de férias e verão), ficando estes jovens expostos, simultaneamente, a dois subsistemas ou ambientes sociais sobrepostos, mas em um mesmo espaço físico (praia), a saber: o contexto do lazer em família e o contexto da prática dos surfistas. Este último é onde os membros do grupo social de praticantes ou da comunidade de surfistas executam sua prática de surfe, interagem entre si e exibem seus modos de pensar e agir, ou a cultura dos surfistas.

Estudos têm evidenciado que familiares e amigos influenciam positivamente as crianças e jovens para ingressarem no esporte. São os pais os maiores responsáveis em proporcionar as primeiras experiências positivas, bem como as condições e recursos necessários para a manutenção de uma prática esportiva sistematizada (OLIVEIRA, 2014; BAILEY; COPE; PEARCE, 2013; CAVICHIOLLI et al., 2011; NUNOMURA; SMOLL; CUMMING; SMITH, 2011; FRASER-THOMAS; COTÉ; 2008; JOWETT; TIMSON-KATCHIS, 2005; COTÉ, 1999).

No surfe, Amaral e Dias (2008) realizaram entrevista semiestruturada com dez surfistas brasileiros para analisar as formas de acesso e como ocorreu o primeiro contato deles com este esporte. Eles verificaram que as redes de relacionamentos sociais, família e amigos mais próximos foram essenciais para que o surfe fosse apresentado aos investigados. Os significados atribuídos à prática do surfe foram a superação dos desafios, o convívio com amigos, a diversão, o estilo de vida, a saúde e o bem-estar e, principalmente, o contato com a natureza.

Através de entrevistas semiestruturadas, Light (2006) investigou quatro jovens surfistas na Austrália e verificou que familiares e amigos foram determinantes para o ingresso destes jovens na prática do surfe. Todos os pais tinham uma relação prévia com a prática do surfe ou com o clube de surfe investigado. A proximidade entre o local de prática e a residência também foi elemento importante para a adesão ao esporte. 
A experiência de prática profissional (Tabela 1) permite destacar que as primeiras experiências e a inserção destes treinadores na área de ensino do surfe esteve quase sempre ligada a episódios ou situações de convívio sociocultural específicos de prática esportiva. Especificamente, a experiência de prática pessoal e as relações sociais no âmbito do surfe.

Estudos realizados em esportes de alto rendimento nos Estados Unidos e Inglaterra mostraram que a maioria dos treinadores profissionais de baseball, basquetebol e futebol foram jogadores destes esportes, antes de tornarem-se treinadores (MIELKE, 2007). Ainda, Gilbert, Côté e Malett (2006), no estudo de padrões das atividades de desenvolvimento de treinadores, indicam que treinadores de softball, futebol e voleibol dos Estados Unidos apresentam milhares de horas de envolvimento como atletas no contexto esportivo, antes de se tornarem treinadores, sugerindo alguma relação entre a experiência de prática pessoal no esporte e o ingresso na carreira de treinador. Estudos no âmbito da formação de treinadores de jovens em esportes coletivos têm mostrado igualmente uma relação entre a carreira de treinador e a experiência prévia de prática no esporte, (Lemyre et al., 2007; Wright et al., 2007; Ramos et al., 2011).

$\mathrm{O}$ ingresso na carreira de treinador esportivo tem sido o destino de muitos jogadores, à medida que cada esporte possui uma cultura própria. A exposição prolongada das pessoas desde a infância a um contexto específico de prática esportiva favorece a aprendizagem informal dos elementos desta mesma cultura (TRUDEL; GILBERT, 2006).

A afirmação de alguns dos sujeitos deste estudo de que o ingresso na carreira de treinador de surfe decorreu de um processo "natural" de envolvimento e participação neste contexto esportivo, evidencia o caráter sociocultural de aprendizagem e remete ao conceito de comunidades de prática de Wenger (2006), nas quais pessoas se unem para compartilhar um interesse ou paixão por algo, interagindo regularmente para aprender mais a respeito deste domínio de interesse. Segundo o autor, para se constituir em uma comunidade de prática, são necessários: um "domínio de interesse" compartilhado pelos seus membros, (neste caso, o surfe é o domínio); a segunda característica é a própria comunidade (neste caso os surfistas, principalmente); a terceira é a própria prática.

Em uma comunidade pode haver níveis distintos de participação: um grupo mais central; um segundo nível periférico mais ativo; e um terceiro nível mais periférico. À medida que um membro de uma comunidade deseja se tornar um participante pleno, mais ativo, ele avança de um nível mais periférico para um nível mais central. Neste contexto de comunidade de prática são desenvolvidos elementos diversos de uma cultura: linguagem, formas de resolução de problemas, conhecimentos, símbolos, modos de pensar e 
agir, significados e valores, que contribuem para a manutenção nesta cultura.

Assim, sugere-se que os sujeitos deste estudo, desde a sua inserção na cultura do surfe, na infância, têm participado e se engajado em uma comunidade de prática. Pode-se afirmar que, ao ingressarem na cultura do surfe, eles identificaram e adotaram o esporte (domínio de interesse) e seus valores, símbolos, benefícios, significados, conhecimentos sobre o mar e habilidades, que passaram a ser, portanto, do seu interesse. A partir de então eles começaram a se engajar e interagir com amigos e pares surfistas (comunidade), para aprender mais sobre como praticar o surfe (prática), tornando-se verdadeiramente surfistas (um lugar mais central e pleno na comunidade de prática).

$\mathrm{O}$ ingresso e permanência destes surfistas no ensino do surfe podem ser interpretados como iniciativas para eles se manterem no "centro" da comunidade, continuando a criar, interagir com outros surfistas e com os modos de pensar e agir da cultura da prática do surfe. Assim, pode-se sugerir que estes sujeitos ingressam na carreira de treinadores para se manterem muito próximos do lugar mais central da comunidade e até continuar propagando os significados que eles mesmos atribuem ao surfe.

Segundo Galipeau e Trudel (2004), o conceito de comunidade de prática pode auxiliar na compreensão das relações sociais existentes entre jogadores e treinadores no esporte. Eles sugerem uma Comunidade de Prática dos Atletas ou Praticantes (ACoP) e uma Comunidade de Prática dos Treinadores/Coaching (CCoP), funcionando como dois subsistemas interdependentes dentro do sistema esportivo mais amplo. Cada um(a), tendo um mesmo domínio de interesse (esporte), interagindo e engajando-se em comunidades (amigos praticantes, amigos treinadores), para melhorar sua prática pessoal ou prática profissional.

Os significados de prática pessoal e os respectivos valores mais individuais (realização, estimulação) atribuídos ao ensino pelos sujeitos podem ser considerados como os elementos internos estáveis e impulsionadores para um engajamento espontâneo e autêntico nos dois contextos de prática, seja pessoal ou profissional. Os valores adotados para o ensino favorecem mais ao coletivismo (benevolência, segurança, universalismo), e podem representar a incorporação de novos valores, refletindo o desejo para a manutenção da cultura do surfe.

A interferência dos valores sociais de Schwartz (2005) nos objetivos de ensino também foi verificada por Ramos et al. (2006), ao utilizar entrevista semiestruturada e observação sistemática com três universitários de Educação Física na formação inicial. Os resultados indicaram que todos os investigados expressaram que os valores obtidos durante a sua experiência pessoal de prática esportiva direcionaram suas escolhas a respeito dos 
conteúdos e estratégias selecionadas. Tal fato corrobora com a ideia de que há uma interferência dos valores nos direcionamentos pedagógicos dos professores e treinadores (ENNIS, 1994; GROSSMAN, 1990).

\section{Conclusão}

As primeiras experiências dos sujeitos deste estudo sobre o surfe ocorreram a partir de situações de lazer de verão, em ambiente natural, proporcionadas por relações sociais mais imediatas, especificamente, através de pais, parentes e amigos. A praia, nesta perspectiva, se constituiu em um espaço natural de diversão, de convívio e interação social.

A praia, enquanto espaço de prática aberto e disponível para todas as pessoas, contribui para que vários grupos sociais convivam de forma simultânea, influenciando-se mutuamente. O interesse dos familiares neste espaço promove o encontro das crianças com os praticantes de surfe e demais elementos da cultura deste esporte.

Os significados atribuídos à prática do surfe por estes sujeitos, desde a infância, mostraram-se estáveis ao longo da sua trajetória de vida, influenciando decisões importantes na sua vida adulta, particularmente na escolha $\mathrm{e}$ permanência na carreira de treinador e a sua prática pedagógica, buscando desenvolver nos seus alunos os seus próprios objetivos de prática pessoal.

As experiências de prática pessoal forneceram os conhecimentos e a segurança necessários para que os investigados ingressassem no papel de treinador. As relações sociais mais imediatas com os amigos ou componentes de um mesmo grupo social favoreceram a criação de condições para o ingresso na carreira de treinador e a manutenção da interação social dentro deste grupo.

Os significados que os treinadores atribuem ao ensino do surfe têm um caráter mais pessoal e individual, em detrimento de valores de aceitação social e coletivismo. A análise dos significados a partir de critérios axiológicos pode contribuir para a compreensão e sistematização de estruturas pedagógicas para o ensino de conteúdos subjetivos, de caráter socioafetivo, particularmente as crenças e sentimentos.

Para além dos aspectos individuais da trajetória de vida, as decisões destes treinadores estão balizadas por um contexto social de prática específica. O ingresso dos treinadores em um contexto social específico vinculado à prática do surfe, dotado de hábitos, significados, conhecimentos, interesses, valores e crenças que se configuram em uma cultura esportiva, sugere novas investigações para que se possa descrever e compreender em detalhes a aprendizagem que ocorre através das interações sociais entre os membros de um mesmo grupo ou de grupos sociais diferentes. 
A utilização do conceito de comunidades de prática surge como um conceito útil para se interpretar como ocorrem as aprendizagens no esporte, enquanto um processo de participação e engajamento social. $\mathrm{O}$ uso deste conceito pode ser uma possibilidade importante para o estudo do surfe e sua cultura, à medida que estabelece parâmetros estruturais de análise deste contexto de prática, delimitado subjetivamente.

\title{
LIFE PATH OF SURF COACHES: ANALYSIS OF MEANINGS OF PER- SONAL AND PROFESSIONAL PRACTICE
}

\begin{abstract}
The aim of this study was to describe situations of the life trajectory of surf coaches by identifying the meanings they attach to personal and professional practice in sport. We conducted a qualitative study with 11 professionals of recognized. Semi-structured interview was used. Data were analyzed using the content analysis technique. The results show that instances of family leisure were important for entry in the context of surfing. The experiences of personal practice and friends were important to become coaching. It was concluded that some personal meanings of practical of these persons remained stable throughout life influencing the choice and stay in coaching career.
\end{abstract}

Keywords: Social Values. Physical Education and Training. Sports.

\section{TRAYECTORIA DE VIDA DE ENTRENADORES DE SURF: ANÁLISIS DEL SIGNIFICADO DE PRÁCTICA PERSONAL Y PROFESIONAL}

\section{Resumen}

El objetivo de este estudio fue describir las situaciones de la trayectoria de vida de los entrenadores de surf, la identificación de los significados que atribuyen a la práctica personal y profesional en el deporte. Se realizó un estudio cualitativo con 11 profesionales de reconocida competencia. Se utilizó la entrevista semiestructurada. Los datos fueron analizados mediante la técnica de análisis de contenido. Los resultados muestran que ocio y la familia son importantes para la entrada en el contexto de la práctica del surf. Las experiencias de la práctica personal y los amigos son importantes para convertirse en entrenadores. Se concluyó que algunos significados personales de estas asignaturas prácticas se mantuvieron estables durante toda la vida y influenciado en la elección y la estancia en la carrera de entrenador.

Palabras-claves: Valores Sociales. Educación Física y Entrenamiento. Deportes.

Pensar a Prática, Goiânia, v. 17, n. 3, p. 815-834, jul./set. 2014 


\section{Referências}

ABRAHAM, A.; COLLINS, D.; MARTINDALE, R. The coaching schematic: Validation through expert coach consensus. Journal of Sports Sciences, v. 24, n. 6, p. 549-564, 2006.

ALVES-MAZZOTTI, A. J.; GEWANDSZNAJDER, F. O método nas ciências naturais e sociais: pesquisa quantitativa e qualitativa. São Paulo: Pioneira Thompson Learning, 2004.

AMARAL, A. V.; DIAS, C. A. G. Da praia para o mar: motivos à adesão e à prática do surfe. Licere, Belo Horizonte, v.11, n.3, p. 01-22, 2008.

ARNETT, J. J. Adolescents' uses of media for self-socialization. Journal of youth and adolescence, v. 24, n. 5, p. 519-533, 1995.

BAILEY, R.; COPE, E. J.; PEARCE, G. Why do children take part in, and remain involved in sport? A literature review and discussion of implications for sports coaches. International Journal of Coaching Science, v. 7, n. 1, 2013.

BANDEIRA, Marília Martins; RUBIO, Kátia. Do outside": corpo e natureza, medo e gênero no surfe universitário paulistano. Rev. Bras. Educ. Fís. Esporte, v. 25, n. 1, p. 97-110, 2011.

BARDIN, L. Análise de conteúdo. Ed. ver. Actual. Lisboa: Edições 70, 281 p, 2010.

BERTALANFFY, L. V. Teoria Geral dos Sistemas. 3. ed. Petrópolis: Vozes, 1977.

BOGDAN, R. C.; BIKLEN, S. K. Investigação qualitativa em educação: uma Introdução à Teoria e aos métodos. Porto: Porto, 2003.

CAVICHIOLLI, Fernando Renato et al. O processo de formação do atleta de futsal e futebol: análise etnográfica. Revista Brasileira de Educação Física e Esporte, v. 25, n. 4, p. 631-647, 2011.

CÔTÉ, J. The influence of the family in the development of talent in sport. The sport psychologist, v. 13, n. 4, p. 395-417, 1999. 
CÔTÉ, J.; ERICKSON, K.; ABERNETHY, B. Play and practice during childhood. In: CÔTÉ, J.; LINDOR, R. (Eds.), Conditions of children's talent development in sport. West Virginia University: Fitness Information Technology, 2013.

DORSCH, T. E.; SMITH, A. L.; MCDONOUGH, M. H. Parent's perceptions oh child-to-parent socialization in organized youth sport. Journal of Sport and Exercise Psychology, v. 31, p. 444-468, 2009.

ENNIS, C. Knowledge and beliefs underlying curricular expertise. Quest, Champaign, v.46, n.2, p.164-75, 1994.

FORNERIS, T.; CAMIRÉ, M.; TRUDEL, P. The development of life skills and values in high school sport: Is there a gap between stakeholder's expectations and perceived experiences? International Journal of Sport and Exercise Psychology, v. 10, n. 1, p. 9-23, 2012.

FRASER-THOMAS, J.; CÔTÉ, J.. Understanding adolescents' positive and negative developmental experiences in sport. Sport Psychologist, v. 23, n. $1,2009$.

FRASER-THOMAS, J.; CÔTÉ, J.; DEAKIN, J.. Understanding dropout and prolonged engagement in adolescent competitive sport. Psychology of Sport and Exercise, v. 9, n. 5, p. 645-662, 2008.

GALIPEAU, J.; TRUDEL, P. The Experience of Newcomers on a Varsity Sport Team. Applied Research in Coaching and Athletics Annual, p. 166188, 2004.

GAU, L.; KORZENNY, F. An examination of values associated with sports attitude and consumption behavior: an exploratory study. Social Behavior And Personality, v. 37, n. 3, p. 299-306, 2009.

GIBBS, G. Análise de dados qualitativos. Porto Alegre: Artmed, 198p, 2009.

GIL, A. C. Métodos e técnicas de pesquisa social. 6. ed. São Paulo: Atlas, 2008.

GILBERT, W. D.; TRUDEL, P. Role of the Coach: How Model Youth Team Sport Coaches Frame Their Roles. The Sport Psychologist, v. 18, p. 21-43, 2004. 
GILBERT, W.; CÔTÉ, J.; MALLETT, C. Developmental paths and activities of successful sport coaches. International Journal of Sports Science and Coaching, v. 1, n. 1, p. 69-76, 2006.

GRAÇA, A. Conhecimento do professor de Educação Física. In: BENTO, J. O.; GARCIA, R.; GRAÇA, A. (Eds.). Contextos da Pedagogia do Desporto. Lisboa: Livros Horizonte, p.167-252, 1999.

GROSSMAN, P. L. The making of a teacher: teacher knowledge and teacher education. New York: Teachers College Press, 1990.

GUIMARÃES, S. E. R. Motivação intrínseca, extrínseca e o uso de recompensas em sala de aula. A motivação do aluno: contribuições da Psicologia contemporânea, v. 3, p. 37-57, 2001.

HENRIQUE, J.; FREITAS, R. C. Crenças e valores de licenciandos de educação física: análise transversal face às orientações de valores dos professores formadores. In: XVI Congresso Brasileiro de Ciências do Esporte e III Congresso Internacional de Ciências do Esporte, 2009, Salvador-BA. Anais do XVI Congresso Brasileiro de Ciências do Esporte e III Congresso Internacional de Ciências do Esporte, p. 1463-1471, 2009.

HOLT, N. L.; NEELY, K. C. Positive youth development through sport: A review. Revista de Iberoamericana de Psicología del Ejercicio y del Deporte, v. 6, n. 2, p. 299-316, 2011.

JOWETT, S.; TIMSON-KATCHIS, M. Social Networks in Sport: Parental Influence on the Coach-Athlete Relationship. Sport Psychologist, v. 19, n. $3,2005$.

LAKATOS, E. M.; MARCONI, M. de A. Fundamentos de metodologia científica. 7. ed. São Paulo (SP): Atlas, 297 p, 2010.

LEE, M. J.; WHITEHEAD, J.; BALCHIN, N. The measurement of values in youth sport: development of the youth sport values questionnaire. Journal of Sport \& Exercise Psychology, v. 22, p. 307-326, 2000.

LEMYRE, François; TRUDEL, Pierre; DURAND-BUSH, Natalie. How Youth-Sport Coaches Learn to Coach. Sport psychologist, v. 21, n. 2, 2007. 
LIGHT, R. Situated learning in an Australian surf club. Sport, Education and Society, v. 11, n. 2, p. 155-172, 2006.

MACLEAN, J.; HAMM, S. Values and Sport Participation: Comparing Participant Groups, Age, and Gender. Journal of Sport Behavior, v. 31, n. 4, p. 352-367, 2008.

MARTENS, M. P.; WEBBER, S. N. Psychometric properties of the sport motivation scale: an evaluation with College Varsity Athletes from the U.S. Journal of Sport \& Exercise Psychology, Champaign, v. 24, p. 254270, 2002.

MCCALLISTER, S. G.; BLINDE, E. M.; WEISS, W. M. Teaching Values And Implementing Philosophies: Dilemmas of The Youth Sport Coach. Physical Educator, v. 57, n. 1, 2000.

MIELKE, D. Coaching experience, playing experience and coaching tenure. International Journal of Sports Science and Coaching, v. 2, n. 2, p. 105-108, 2007.

MOLINA NETO, V.; TRIVIÑOS, A. N. S.; SANCH, J. M. A pesquisa qualitativa na educação física: alternativas metodológicas. 2. ed. Porto Alegre (RS): Ed. da UFRGS: Sulina, 141p, 2004.

NEGRINE, A. Instrumentos de coleta de informações na pesquisa qualitativa. In: MOLINA NETO, Vicente; TRIVIÑOS, Augusto Nibaldo Silva; SANCH, Juana M. A pesquisa qualitativa na educação física: alternativas metodológicas. 2. ed. Porto Alegre (RS): Ed. da UFRGS: Sulina, p. 61-93, 2004.

NUNOMURA, M.; OLIVEIRA, M. S. A participação dos pais na carreira das atletas femininas de ginástica artística: a perspectiva dos técnicos. Revista Brasileira de Educação Física e Esporte, v. 28, n. 1, p. 125-134, 2014.

O'SULLIVAN, M. Beliefs of teachers and teacher candidates: Implications for teacher education. In: COSTA, F. C.; CLOES, M.; GONZALES, M. (Eds.), The art and science of teaching in physical education and sport. Lisbon: Technical University of Lisbon, p. 149-164, 2005.

RAMOS, V. O treino do basquetebol na formação desportiva de jovens: estudo do conhecimento pedagógico de treinadores. Tese (Doutorado em Ci- 
ências do Desporto) - Faculdade de Desporto, Universidade do Porto, Porto, 2008.

RAMOS, V.; GRACA, A. B. S.; NASCIMENTO, J. V. A representação do ensino do basquetebol em contexto escolar: estudos de casos na formação inicial em educação física. Revista Brasileira de Educação Física e Esporte, v. 20, p. 37-49, 2006.

RAMOS, V.; NASCIMENTO, J. V.; GRACA, A. B. S.; SILVA, R. A aprendizagem profissional - as representações de treinadores desportivos de jovens: quatro estudos de caso. Revista Motriz, Rio Claro, v. 17, n. 2, p. 280291, 2011.

ROKEACH, M. Crenças, atitudes e valores. Rio de Janeiro: Interciência Editora, 1981.

SCHWARTZ, S. H. Valores Humanos Básicos: seu contexto e estrutura intercultural. In: TAMAYO, A.; PORTO, J. B. (Orgs.), Valores e comportamento nas Organizações, Petrópolis: Vozes, p. 21-55, 2005.

SMOLL, F. L.; CUMMING, S. P.; SMITH, R. E. Enhancing coach-parent relationships in youth sports: Increasing harmony and minimizing hassle. International Journal of Sports Science and Coaching, v. 6, n. 1, p. 13-26, 2011.

THORPE, H. 'Beyond decorative sociology: contextualizing female surf, skate and snowboarding'. Sociology of Sport Journal, Champaign, v.23, n.3, p.205-28, 2006.

TRUDEL, P.; GILBERT, W., Coaching and Coach Education. In: KIRK, D.; MACDONALD, D.; O'SULLIVAN, M. (Eds.). The Handbook of Physical Education. London: SAGE, p. 516-539, 2006.

TSANGARIDOU, N. Trainee primary teachers' beliefs and practices about physical education during student training. Physical Education and Sport Pedagogy, v. 13, n. 2, p. 131-152, 2008.

WRIGHT, Trevor; TRUDEL, Pierre; CULVER, Diane. Learning how to coach: the different learning situations reported by youth ice hockey coaches. Physical education and sport pedagogy, v. 12, n. 2, p. 127-144, 2007. 
Recebido em: 09/06/2014

Revisado em: 30/06/2014

Aprovado em: 11/07/2014

Endereço para correspondência:

valmor.ramosr@udesc.br

Valmor Ramos

Universidade do Estado de Santa Catarina - UDESC / Av. Madre Benvenuta, 2007 Itacorubi - Florianópolis - SC

CEP: 88.035-001 